\title{
THE AUDIOMETER AND THE MEDICALISATION OF HEARING LOSS
}

\section{Units of sensation}

When I was around seven years old, we went on a family trip to Aberdeen Science Centre. My memory of that day has largely faded, but I now know that something significant happened on that trip. One of the exhibitions featured an umbrella-style speaker used to demonstrate the normal ranges of human hearing. Human hearing is, as this book should have already made clear, a complicated topic. What we can hear depends both on loudness (decibel levels) and pitch (frequency levels), as well as a variety of other factors. This speaker was set up to gradually increase in frequency, so that it progressed from tones such as those you would hear on a standard piano, through to higher sounds like that of a microwave beeping, to end with barely audible tones of around 20,000 Hz. While Dad, my brother and I were laughing and joking about how long we could hear birdsong and so on, Mum was realising her hearing range had cut out long before ours. It was a strange way, no doubt, to find confirmation of one's deafness.

The kind of technology that was used in this display relies on the standardisation of electronic sound, which was perfected and pursued in the interwar years as the audiometer was embraced as an objective tool to define noise limits and thresholds. Its utilisation of fixed thresholds for the normal ranges of hearing were also, as I explain in the section that follows, fixed through 'the telephone as audiometer'. The audiometer was elevated as a tool for testing both noise levels and hearing loss, I argue, because it provided an objective numerical inscription, which could be used to guard against malingering and to negotiate compensation claims for hearing loss. It was also as utilised in the prescription of hearing aids and, as I show in the section on 'The telephone as hearing aid', the interwar period featured an explosion of hearing aids based on 
telephone technologies, which led to the increased medicalisation of deafness as the medical community sought to temper the 'quack' hearing aids flooding the market. However, the medicalisation of hearing aids was no simple matter. Such medicalised prescription was complicated by conflicts over categorisation, the status of hearing aids as medical devices and the question of which institutional bodies were responsible for the 'problem of hearing loss'. The Post Office, telephone engineers, hearing aid manufacturers, the Ministry of Health, the MRC and the NID were all embroiled in this debate, as each body sought to temper the explosion of hearing aid devices available for those with hearing loss in the interwar period. Even the Ministry of Pensions was involved in their distribution, as it started supplying hearing aids to deafened ex-servicemen as a supplement to or replacement for a full pension. Moreover, because hearing aids were variously categorised as either medicines, prosthetics or technological apparatus, their categorisation was mutable and subject to politicisation. In the section on 'Advertising hearing aids', I explain that this meant that the Post Office was able to legally advertise so-called 'quack' hearing aids with impunity. Simultaneously, the Post Office engineers' growing expertise in auditory technologies meant that they were concurrently involved in the design of the first NHS hearing aid - the Medresco. In the section on 'Putting the user in the picture', I analyse the ending of the Post Office's amplified telephone service, and argue that their failure to consider user input or the reality of hearing aid usage from the perspective of the 'deaf subscriber' led to their failure to provide an NHS adjunct for telephony. In the conclusion to the chapter, I argue that this has had profound consequences on our elevation of access to face-toface speech above access to sound technologies such as telephony or music.

In the previous chapter, we explored the extent to which the British Post Office's artificial ear technology defined normal hearing in the telephone system. In this chapter, we move beyond the Post Office to reflect on the way that this mechanistic understanding of hearing impacted wider society, by analysing how the audiometer developed from the telephone, worked to medicalise hearing loss and was used to calibrate and prescribe hearing aids.

Inventions including the microphone, the vacuum tube and the condenser transmitter ushered in a new wave of electro-acoustic tools over the course of the 1920s; these were tools which 'not only provided acoustical researchers new means by which to study sound' but also 'new models for thinking about it.' ${ }^{\prime}$ In the early 1920s, sound was measured in ambiguous noise or sensation units. These were obtained through the use of a rudimentary audiometer, which the recorder would turn up until the tone was loud enough to mask the ambient noise around them. ${ }^{2}$ This gave a proxy measure for the environmental noise levels. But this was inadequate, as Post Office research engineer W. West 
explained in a 1933 lecture to the Post Office Telephone and Telegraph Society of London. ${ }^{3}$ West argued that although instruments could be constructed to record objective measurements of noise, this kind of measurement would not capture frequency levels, nor the quality of noise disturbance as perceived by an individual, therefore, 'this reading will not necessarily bear any close relation to the loudness as heard by the ear. ${ }^{4} \mathrm{~A}$ better method, he proposed, made use of an 'observer' provided with: 'a standard tone - say a pure tone at 1000 cycles per second in a telephone receiver - and if he has also an attenuator to vary the magnitude of this tone by known amounts, he can adjust the attenuator until he judges the standard tone to be as loud as the noise to be measured'. 5 $\mathrm{He}$ argued that this could be done by a number of observers, with the average results giving the 'frequency characteristics of normal hearing.' ${ }^{6}$ Thus, this method, originally used by telephone engineers to measure electrical noise on transmission lines, was used to measure noise levels in the city. ${ }^{7}$ West further pointed out that by the 1930s, an objective measurement of sound was becoming more important, as 'the standardization of noise units and loudness units is at present under discussion in this country.' Indeed, this kind of individual subjective measurement was gradually superseded during these decades with the rise of decibel measurement, a term coined in 1923 by Bell Laboratories in the US and then gradually adopted by the UK. ${ }^{9}$

These broad shifts towards increased objectivity and accuracy in sound measurement were also apparent in hearing testing, as the interwar years featured a broader drive for a standard criterion of sound. ${ }^{10}$ The Post Office Engineering Department was particularly motivated to replace data based on the kinds of individual patterns of use we discussed in Chapter 3 with more quantifiable data concerning sound, hearing and hearing aids. Simultaneously, standardisation of the measurement and definition of sound was necessary to provide proof of the levels of noise pollution, which was of intensifying concern during the interwar period. Emily Thompson has shown that instruments designed to measure noise actually worked to redefine the meaning of sound, as the 'problem of noise was further amplified in the 1920s by the actions of acoustical experts. ${ }^{11}$ For an example of this, we can look back at West's Post Office paper, which included a 'noise chart' showing the progression of noise levels in different types of spaces, ranging from the 100 decibel 'noisy aeroplane cabin', the 60 decibel 'steam train (window open) to the 40 decibel 'quiet saloon car (30MPH) ${ }^{\prime}{ }^{12}$ However, his measurements included decibel units as well as indicators of the 'threshold of feeling', which was measured in dynes per sq. cm. ${ }^{13}$ Thus, units of sound measurements were unstable in 1933, yet by the latter years of the 1930s the decibel was fixed in use to describe sound and hearing loss both in the telephone system and in the human body. As this 
chapter will explore in more detail, the decibel standard for measuring hearing loss was fixed in large part as a result of the influence of the telephone companies. These shifts in quantifying and assessing sound levels echoed deeper changes in the way that hearing was conceptualised by both engineers and otologists. Post Office engineers wielded great influence in building such new mechanistic models of sound, which were then incorporated into their interpretation of what constituted hearing loss in the medical sphere.

\section{The telephone as audiometer}

A way of using objective technology to define and diagnose deafness was sought out long before the field of audiology professionalised after the Second World War. In this section, I outline the longer history of using technology to diagnose deafness through discussion of the beginnings of otology, before elucidating how the audiometer was eventually embraced as a trusted instrument to secure levels of hearing loss for compensation in numerical terms in the industrial/military context.

Treatment and diagnosis of deafness in the early nineteenth century was difficult, and this difficulty fostered instability in the fledgling field of otology and in aural surgery.$^{14}$ Historian Jaipreet Virdi has explained that one of the ways that nineteenth-century aurists attempted to legitimise their work as scientific was by appealing to their use of technology. ${ }^{15}$ Later in the century otology established itself as a specialism, and its practitioners began using tuning forks to establish both frequency loss and type of hearing loss. ${ }^{16}$ Tuning fork tests thus gave qualitative as well as quantitative results. However, it was the 1879 invention of the audiometer by Welsh scientist David Edward Hughes (1831-1900) that ushered in the means to make large-scale quantitative surveys on hearing loss. ${ }^{17}$ Hughes's instrument attached the telephone to a horizontal bar adorned with two coils, which set up an induction current linked to a battery and microphone, meaning that the current could be heard through the telephone as a tone. ${ }^{18}$ When the induction coil was nearer one end of the bar (and the larger coil) the sound was louder, and the sound decreased when it moved in the opposing direction. ${ }^{19}$ Hughes introduced his instrument to the medical profession and emphasised to the Royal Society 'the value of the instrument as an absolute measure of our hearing powers. ${ }^{20}$ This early version of the audiometer measured hearing on a scale based on the division of the bar into 200 parts, so hearing could be tested from the maximum of 200 units to absolute zero. ${ }^{21}$ However, as historian Michael Kay has pointed out, the nineteenth-century audiometer was largely rejected by practitioners, who disliked its expense, complexity and inconvenience. ${ }^{22}$ Tests using tuning forks, 
the watch tick test or the spoken voice (Snellen) test were considered by most clinicians to be far simpler. Debates over the utility of these tests intensified in Britain after the First World War, when doctors were faced with treating soldiers suffering from both noise-induced hearing loss and temporary hearing loss caused by shell shock.

Rather than in its initial iteration, it was therefore during the interwar period that the audiometer was repeatedly lauded as a significant advance in the diagnosis and classification of deafness. ${ }^{23}$ In 1928, the aural surgeon (and founder member of the Socialist Medical Association) Mr Somerville Hasting advocated in the British Medical Journal for the need for standardisation, emphasising that 'from the point of view of scientific advance, arbitrary units of hearing must be given up. ${ }^{24}$ The audiometer's ability to provide quantitative units of hearing ability and to allow for their comparison was especially valuable in achieving this, as one American otologist explained: 'The invention of the telephone and its universal use offered a means for producing a sound which could be standardized and measured. ${ }^{25}$ This was a clear advantage compared to the more commonly used voice test, which could not be standardised and necessitated the involvement of the clinician's own (variable) body. In 1931, the NID's medical sub-committee highlighted the importance of standardisation to argue that hearing should no longer be tested through the unreliable and subjective medium of the voice:

In view of the improvement in the making of gramophone records, in gramophone and in methods of transmission of speech sounds to the ear by telephone, the committee feel that it should be possible so as to standardise gramophone records and the speech intensity delivered to the ear so as to produce a standard of hearing for speech ... Inasmuch as the decibel index of speech sounds by telephone has been adopted by international agreement between the various telephone services, the committee recommend that this index should be the basis of measurement and description of standard speech intensities used for testing hearing for speech. ${ }^{26}$

The above quotation highlights the extent to which hearing testing was actively influenced by developments in sound recording technologies and especially by telephony and telephone companies.

Moreover, the audiometer produced an audiogram, through which otologists could establish at last the 'facts' of 'normal hearing. ${ }^{27}$ The audiogram rendered the 'quantitative measurement of hearing' in graphical form, allowing for the recording, reproduction and graphical comparison of hearing. ${ }^{28}$ For some of its proponents, the value of this inscription for research purposes lay precisely in the fact that it circumvented the need to rely on the testimony of 
those with hearing loss, for example in instances where, as a report in The Lancet explained, 'the effect of drugs may be recorded graphically instead of having to rely on the statements made by patients. ${ }^{29}$

As a result, I argue that the audiometer can be considered as a model instrument to wield in promotion of the kind of 'mechanical epistemic injustice' explored in Chapter 2. Related to this was the audiogram's status as an 'objective test' that could be used to prevent malingering, which deafness had long been associated with. The suspicion attached to deafness in the interwar years was compounded by its invisibility, alongside

the fact that there is no known objective test by which hearing power or its absence can be measured. With the blind the statement of the person under examination can be subjected to corroboration by instrumental tests in which he has no say; but the deaf subject must be left to give his answers unchecked, even when the watch or whisper tests, or the use of graded tuning-forks are employed. In fact the only way to detect the malingerer is by the familiar test of making a loud noise behind the subject in order to elicit a surprise. ${ }^{30}$

Hearing loss thus posed a problem related both to the subjectivity of the individual body and its invisibility outside of the individual body. The lack of tests to catch supposed malingerers became particularly problematic in the First World War because of the difficulty of diagnosing 'hysterical' deafness in soldiers. In 1915, Dr William Alden Turner wrote to the British Medical Journal to describe 'Cases of Nervous and Mental Shock' and included a section on 'Deafness and Deaf-Mutism. ${ }^{31}$ Turner was influential, acting as consultant neurologist for the War Office from January 1915 and later becoming the adviser for the Ministry of Pensions on matters concerning neurology after the war. ${ }^{32}$ Turner noted that this kind of deafness comprised 'one of the clinical surprises of the war' and that 'examination of the sense of hearing reveals deafness of the nervous type. ${ }^{33}$ Wartime hearing loss was thus considered to be psychosomatic or 'functional', which meant that the underlying pathological cause could not be seen, but, crucially, was supposed to exist. Such an ideology was in line with psychiatry's long-standing insistence that there was a fundamental bodily cause for all mental illness. ${ }^{34}$ In 1917, the editor of The Lancet similarly expressed the opinion that 'the present war has made us acquainted with new varieties of deafness. ${ }^{35}$

Treating hearing loss alongside shell shock in the First World War led to conflict between psychiatry and otology. ${ }^{36}$ Hearing loss gained new visibility within the public consciousness and became a high-profile issue precisely because it was intimately bound up with the visible and disturbing new condition of shell shock. As it became increasingly apparent that shell shock had 
psychological origins, the idea that hearing loss was also psychological gained increased credence within psychiatry. This led to a wave of new theories about the causation of hearing loss, and correspondent new treatments to test and treat the malingerers so that, as historian Julia Enke has put it, 'after the noise, the soldiers' ears were beleaguered by medicine. ${ }^{37}$ Treatments and diagnoses of these new varieties of deafness were split between more traditional treatment favoured by aural surgeons and the treatments favoured by psychiatric practitioners. On the side of traditional otology, aural surgeons Dr A. Logan Turner and Dr P. McBride (ear and throat surgeon and consulting surgeon respectively, at Edinburgh Royal Infirmary) classified hearing loss purely as injuries of the internal ear, middle ear or tympanic membrane and considered middle-ear deafness to be nerve deafness. ${ }^{38}$ Turner and McBride wrote to The Lancet in 1918 to criticise the new ideas about deafness circulating within the wider medical profession. They made the case that wartime hearing loss was organic, and argued that: 'very grave injustice might be done if the dictum were accepted that given a man deaf from explosion, if he reacts to the vestibular tests in what his examiner considers a normal manner he is therefore either a malingerer or the victim of hysteria. ${ }^{39}$

However, differentiating between malingering and hysteria was itself difficult, as we can gather from neurologist Arthur Hurst and aural surgeon E. A. Peters's attempts to test one of their sleeping patients by "by shouting "fire", and by banging a poker against a coal-scuttle within a few inches of his head' $!^{40}$ The category of 'hysterical' deafness was particularly fraught in the military context, as medical officers were generally highly suspicious of 'malingering' and hysteria was often considered to simply be a form of unconscious malingering. The audiometer offered a more reliable way to test malingering, and instructions to this effect were given as part of the kit for the 1940s commercial Amplivox audiometer shown in Figure 4.1. Amplivox was a successful hearing aid company and would have used an audiometer like this primarily to prescribe hearing aids. However, the instructions accompanying it emphasised its utility to those involved in moderating contested hearing loss and they explained that 'malingerers feign deafness in various degrees and for various reasons. ${ }^{41}$ Several strategies could be adopted to detect and confound the malingerer, including hiding the front panel from the patient's view, using the tone interrupter (Figure 4.1, bottom right) so that the patient would be unable to remember previous tone intensities, and by switching tones from ear to ear and from air to bone conduction, which 'easily confuses the subject and makes it practically impossible to deceive the operator. ${ }^{2}$

Similarly, the audiometer enabled detection of those who could 'pass' as hearing by lip-reading. ${ }^{43}$ This was especially valuable in the testing of 


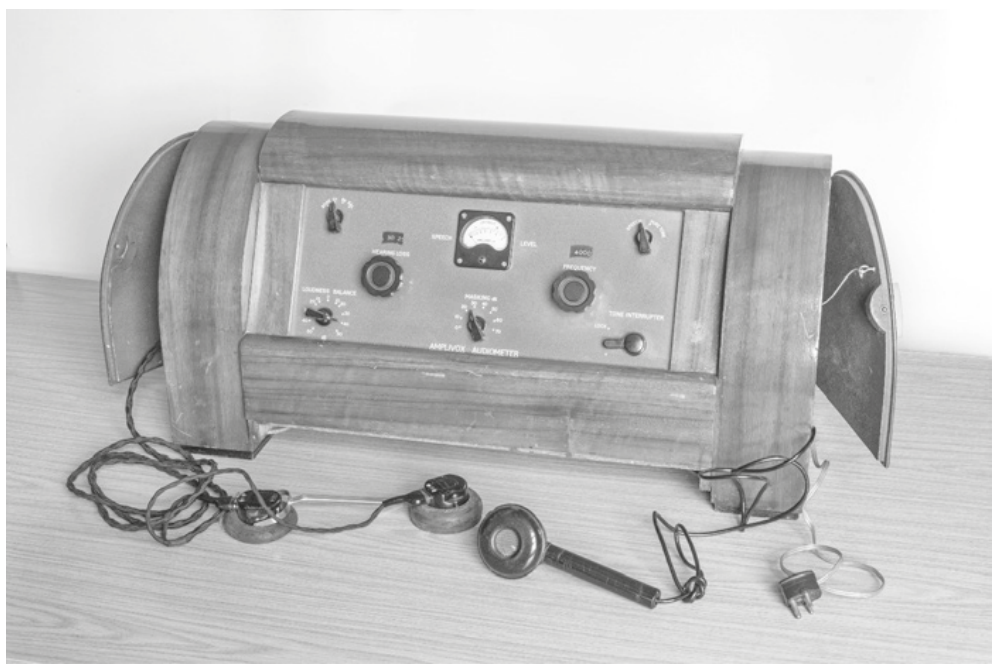

Figure 4.1 Audiometer

school-children, who could be tested rapidly and in larger groups with the audiometer. ${ }^{44}$ This resulted in an increase in the more 'precise' sorting of children, 'who were found to be defective' and so reclassified. ${ }^{45}$ In this way, the audiometer worked as an inscription device, an apparatus whose end-product was the audiogram and the creation of 'Normal Hearing' and, crucially, its counterpart. ${ }^{46}$ We can see in this way how the power of the audiometer as a classifying device influenced the social construction of disability, which was reinforced as the audiometer created more data on normal hearing, a process I now discuss in more detail.

As historian Mara Mills has shown, the necessary data came first from American telephone companies, who produced the Western Electric 1A audiometer in 1922, considered to be the first commercial electronic audiometer. ${ }^{47}$ This was lauded by many British otologists as a great step forward. For example, leading British otologist Dr Wharry Crowden acknowledged that the Bell Telephone Company had 'helped the medical profession greatly by producing a reliable audiometer which is now being effectively used. ${ }^{48}$ One of Bell Laboratories' foremost researchers, Harvey Fletcher, clarified that a unit for measuring sound in a standardised fashion was necessary for the telephone business, in which 'the commodity being delivered to the customers is reproduced speech. ${ }^{49}$ The standard unit eventually adopted was, of course, the decibel, ten of which make up a bel - named for Alexander Graham Bell. ${ }^{50}$ As I have 
previously argued with Virdi, through this standardisation the audiometer came to represent 'a new mechanistic understanding of auditory perception, one that merged a physical instrument with a more precise and measurable way of tracking perceptions of sound. ${ }^{51}$

As The Lancet recognised in 1933, advances in audiometry interrelated with developments in sound reproduction techniques more broadly, which were used not only in telephony but also in radio. ${ }^{52}$ For example, the vacuum tube (in American English) or valve (in English) was essential in advancing the construction of radios, audiometers and telephony during this period. Yet, as the NID's medical committee noted in 1926, such technical advances were utilised in sound technologies which further isolated those with hearing loss:

The frequent press references to wireless telephony as a curative agent in deafness induces your Committee to make the following observations on the matter. Wireless is of no use to the deaf-mute. In cases of hardness of hearing, those who hear through the ordinary telephone will hear wireless through its earphones; and those who have difficulty with speech, heard through the air, will have the same difficulty with the loudspeaker. There is, no doubt, a percentage of hard of hearing persons who experience pleasure from listening to wireless speech and music but the sensational promises of relief, often disseminated through the Press, lead only to disappointment and add to the burden of the affliction. ${ }^{53}$

Nevertheless, such technical developments were incorporated into otology alongside techniques for testing transmission quality pioneered by the British Broadcasting Company (the BBC) ${ }^{54}$ For the MRC, the audiometer offered a way to 'merge clinical research with scientific efficiency', and it became central to their interwar hearing committee's projects on normal hearing and its potential restoration. ${ }^{55}$

The audiometer was also critical to the interwar commitments of deaf educators and especially fuelled the legitimacy of the commitment to oralism, an educational method that prioritised speech and lip-reading to 'normalise' deaf children and force their integration into the hearing world. ${ }^{56}$ It was further embraced by the industrial/military nexus as a way of arbitrating compensation for hearing loss, as it was determined to be useful as a means of identifying 'impaired hearing' and hence 'the unfitness of applicants for insurance policies, automobile licenses, and for enlistment in the Army and Navy, also in the life protection tests of railroad and steamship companies, and in the health corrective examination of schools, colleges, and gymnasiums. ${ }^{57}$ Indeed, the field of audiometry frequently identifies its origins as truly lying in the Second World War, when it was embraced by the US military for compensation purposes to provide a numerical assessment of hearing loss before and after service, which 
was critical to the management of compensation claims. In the military it was necessary to test many people quickly and have a numerical result that could be compared before and after service in order to award or refuse compensation for noise-induced hearing loss. Audiology then solidified as a field through the work done with deafened ex-service men during the war. ${ }^{58}$ That compensation required the creation of numbers to indicate critical thresholds of disability is a key component of this book's main thesis, as this process worked to categorise disability, and did so in a way which discounted the need for individual testimony.

Despite the fact that the Second World War is frequently cited as the starting point for audiology, there are clear precursors to its development in the interwar years; in audiologist Berger's terms, the field 'existed some years previously, but without a special name. ${ }^{59}$ One contemporary clinician wrote in The Lancet in 1934 that 'the great advances in the precision of electrical instruments for amplifying and transmitting sounds have all been made since the War. ${ }^{60}$ As Emily Thompson has shown, the First World War worked as a catalyst to stimulate acoustical researches in America, which in turn stimulated the design of new instruments to detect and measure sound. ${ }^{61}$ In Britain, however, the nascent field of audiometry primarily developed in the interwar years through the encouragement of the scientist Dr Phyllis Kerridge, who perhaps more than anyone else advocated for more scientific methods for testing hearing. ${ }^{62}$ Kerridge was the first person in Britain to own a Western Electric (pure tone) audiometer, and she used this to conduct statistical studies on hearing thresholds, moving hearing loss into the realm of medicine by considering hearing loss as a 'legitimate scientific problem worthy of technocratic intervention. ${ }^{63}$ Kerridge's plans to define 'normal hearing' were based on her faith in precise and 'exact measurement' and she introduced her MRC investigation on Hearing and Speech in Deaf Children by invoking the infamous 'curse of Kelvin' (discussed in Chapter 1). ${ }^{64}$ She used this investigation to compare different methods of testing hearing, and questioned the validity of the 'normal' level of hearing set by the audiometer, noting that:

There is no indication in the literature of the degree of variation among the 'normals. The same remark applies to the 'normal' bone conduction line. Further, it is an assumption that lines are the same for children as for adults. ${ }^{65}$

As Kerridge was using a Western Electric audiometer this meant that the average threshold level was set according to the Bell Laboratories. ${ }^{66}$ Normal hearing was calibrated to 'the average child in the average classroom. ${ }^{67}$ As her remarks make evident, Kerridge not only recognised the danger of equating the average with the normal, but also highlighted the need to use different 
normalcy levels for different groups, such as children or the elderly (see Chapter 2). She questioned the assumption that the zero line representing normal hearing was universal for all peoples of all ages and sexes, and 'demonstrated the arbitrariness of its construction. ${ }^{6} 8$

Kerridge's pioneering techniques were used in the prescribing and moderation of hearing aids, which she argued needed to be standardised within medicine. ${ }^{69}$ In the spring of 1937, she opened the first hearing aid clinic in Britain, where she fitted patients for hearing aids based on their audiograms, taking the responsibility of hearing aid prescription away from commercial firms. ${ }^{70}$ Kerridge thus addressed the lacuna that Dr D. F. Fraser-Harris (professor of physiology) had highlighted in 1934, when he noted that

\begin{abstract}
strange as it may appear, there is no body of persons qualified to interpret an aurist's prescription for a deaf patient, and to supply the appropriate deaf aid instrument, as there are opticians able to read an oculist's prescription and to provide the spectacles specified. Just as it requires a specialist - the oculist - to ascertain the precise nature and amount of departure from normality in vision, so it requires a skilled person to ascertain the precise kind and degree of deafness from which a deaf patient may be suffering. The reason for this difference is that the science of optics has been developing for about the last two hundred and fifty years. ${ }^{71}$
\end{abstract}

In contrast, as the next section will outline, regulation of hearings aids was in a state of flux during the interwar years, as the viability of electrical hearing aids rapidly improved during this period.

\title{
The telephone as hearing aid
}

From their initial instantiation as 'micro-telephones', electric hearing aid devices became increasingly viable in the interwar period. ${ }^{72}$ This increase in viability is evident in analysis of the hearing aids distributed to deafened ex-service men by the National Benevolent Society (discussed in the previous chapter), which administered the Deafened Ex-Service Men's Fund. Use of electrical hearing aids by their members increased rapidly year upon year according to the society's reports: from no reports of use between 1921 and 1923, to 73 earphones issued in 1932 and 162 in $1939 .^{73}$ This increase could be explained by the technical developments that led to increased manufacture of electrical hearing aids during the 1930s. However, the National Benevolent Society itself attributed the increase to 'so many of the slightly deafened men of twenty years ago becoming so deaf that they are in danger of losing their employment.' ${ }^{74}$ 
The first mention of their use came in 1924, in a testimonial from a soldier who wrote, 'I have great pleasure in informing you that I have been fitted with a Stools [sic] electrophone by the Ministry of Pensions. ${ }^{75}$ The government had advocated lip-reading for deafened ex-servicemen since 1917 because of growing concern about national productivity, as the industrial effectiveness [of soldiers] has been seriously impaired by deafness due to military service. ${ }^{76}$ Centres of instruction for lip-reading were set up in response, but very few exservicemen applied for classes or accepted them when offered. This prompted the Ministry of Pensions to set up a special aural board, which became instrumental in allocating the distribution of hearing aids and pensions. ${ }^{77}$ The first official ministry ruling on hearing aid supply came in 1922 in response to an enquiry from the commissioner of medical services for the ministry, who asked whether hearing aids could be charged to their account. ${ }^{78}$ Sir Dundas-Grant (1854-1944), director general of medical services, wrote in response that

[if the hearing aid has] been recommended by a specialist member of the board which examined him [then] supply is admissible at the public expense and the article may best be obtained from the Stols Electrophone Company ... with whom the Ministry have a special arrangement and who are prepared to supply these appliances to our order at a discount of $20 \%$ on the list price. $^{79}$

Supply of batteries was also subsidised by the ministry but was closely controlled, with a restricted number of batteries (soldiers were allowed two a month), which presumably also restricted the level and type of usage. Many hearing aid firms wrote to the ministry to try and solicit its endorsement and stressed that they offered one price to the ministry and the medical profession and another price to the public. As the Mears earphone manufacturers put it, 'we only hand these to Medical Men, not to the public.8 ${ }^{80}$ This meant that, as in the case of charitable provision, deafened servicemen were given consideration and support that did not extend to deafened civilians.

In 1922 the Ministry of Pensions spent $£ 100$ on hearing aids, but three years later this figure had risen to just over $£ 1362 \mathrm{~s} 9 \mathrm{~d} .{ }^{81}$ The sum spent on hearing aids was to increase exponentially throughout the interwar years as electrical aids were increasingly used by the ministry as supplements or alternatives to a full pension, and as a means of reintegrating vast numbers of ex-servicemen with hearing loss into the workforce. The ministry's relationship with hearing aid suppliers offers a fascinating snapshot of how state hearing aids were provided before there was a state hearing aid. Moreover, it demonstrates that state intervention into hearing loss increased alongside developments in hearing aid technology that were thought to provide a quick and cheap 'fix' for deafness. Yet before the instigation of the NHS, there were still great discrepancies 
between the care given and the care needed. As Gooday and Sayer point out, most of the government pensions granted to ex-servicemen were dedicated to 'those who had lost limbs, eyes, or been facially disfigured.82 Charitable provision was left to address the needs of the others. The records of the National Benevolent Society in 1928 reported that 'the latest official figures show that 33,768 men were discharged from the Army and Navy on account of deafness. ${ }^{83}$ The increased visibility of deafness in returned soldiers helped to normalise hearing loss and make the deafened more of a priority for social welfare. Indeed, the classification of those with hearing loss solidified after the First World War into a new category - the 'deafened'. As Gooday and Sayer have argued: 'Deafened combatants were not treated as being genetically predisposed to loss of hearing, but the honourable victims of the damaging percussive effects of artillery. ${ }^{84}$ Yet the stigma associated with deafness was still high, especially for women and the congenitally deaf, who were targeted in this period as a problem for eugenicists.

That the stigma surrounding deafness during the interwar years was still great is evident from the lengths that those with limited hearing would go to in order to identify as hearing and minimise the significance of their hearing loss. It is further manifest in the rhetoric attached to advertisements for hearing aids during the interwar period. Hearing aid companies made exaggerated claims, using vivid language and images to persuade customers of their devices' effectiveness. These advertisements relied for their effectiveness on the socially constructed imperative that such disability should be concealed. ${ }^{85}$ This imperative was exacerbated at the start of the twentieth century as stigmatisation of deafness increased alongside industrialisation's demands for standardised practices. As Gooday and Sayer explain, this demand meant that deaf people had to 'adapt to the hearing world's oral norms or face marginalisation in unemployment. ${ }^{86}$

A common trope in such advertisements was to draw on the stigma of deafness to sell the product by emphasising the inconspicuousness and invisibility of the hearing aid. ${ }^{87}$ The 'micro-telephone' by the Stols Electrophone company, for instance, was advertised as such:

$[F]$ or those who require a hearing aid that can be worn inconspicuously we recommend the micro-telephone illustrated above. In use, it can be concealed under the coat or blouse, and a midget ear-piece no large than a sixpence can be applied to fit closely in the ear and which, in the case of a lady can be completely concealed by the hair. ${ }^{88}$

Similarly, the makers of the fortiphone urged its users to be, 'free from the embarrassment associated with clumsier devices. ${ }^{89}$ One American otologist 
hyperbolically underscored the fact that 'the public is not wont to employ people with a telephone stuck on one side of their heads. ${ }^{90}$ For women, there were additional imperatives driving concealment. For example, the 'Mears Ear-Phone' was depicted in one advertisement held like a delicate fan against the ear of a beautiful woman with an ornate hairstyle, while the gentleman next to her leaned close to her and whispered (into her other ear!). Below this image was the caption 'A complete success: enjoy the pleasures of sound again.' ${ }^{11}$ This exemplifies the additional gendered imperative that such advertisements frequently invoked, which compelled women to wear hearing aids that would conceal their hearing loss and allow them to compete and 'succeed' on the marriage market.

The stigma attached to conditions like hearing loss was complicated by the fact that it was ostensibly invisible, and offered the potential to remain so for the sufferer who chose not to accept assistive equipment. ${ }^{92}$ Hearing loss was only apparent if the person with hearing loss chose to expose it, which was not always the best course of action. ${ }^{93}$ Moreover, in the case of hearing loss there was an added pressure to use hearing aids so as to avoid inconveniencing others in conversation. ${ }^{94}$ As Mills has argued, the hearing aids construction as a 'stigma symbol' drove the increased miniaturisation of electrical aids, while their increased usage augmented the number of those who identified as 'hearing' or 'hard of hearing' rather than Deaf. ${ }^{95}$ It is worth noting, however, as Gooday and Sayer have discussed, that there are always 'two stories' that can be told about hearing aids. And while a story about increased miniaturisation and stigma is certainly evident (particularly during the interwar period), it runs alongside the stories of those who wielded their hearing aids as powerful prosthetics that allowed them to dictate the terms of the conversations they were involved in and the people that they allowed to engage with them. ${ }^{96}$ Indeed, Mills stresses that there are many examples of hearing aid users controlling and directing conversations, and that, 'Deaf and hard of hearing people played shaping roles as early adopters, inventors, retailers, and manufacturers of miniaturized components. ${ }^{97}$

Yet the growing popularity of electric hearing aids led to a subsequent proliferation of unscrupulous electrical hearing aid manufacturers; the controversial practices of some of these firms resulted in the medical profession taking a more active interest in the regulation of their distribution. Such divisive practices included the work of those who were widely derided as 'quacks', that is, hearing aid vendors who exaggerated their ability to cure deafness in a way that sparked the ire of the medical community. ${ }^{98}$ As Kerridge baldly put it in 1935: 'The commercial hearing aids may be roughly divided into those that are frauds and those which are not. ${ }^{99}$ The electrical hearing aids designed 'on the telephone principle' were criticised by Kerridge on a number of points. They 
magnified sounds only by about 20-60 decibels and this magnification took place 'mostly in the middle frequencies', despite the fact that most adults with hearing loss were unable to access the higher frequencies. ${ }^{100}$ As a result, she noted that 'they have been the cause of such a lot of hope and disappointment to deaf people.' ${ }^{101}$ They also gave the voice a less natural, more mechanical quality, and Kerridge quoted one of the children she had lent such an instrument to, who responded that it 'made her teacher sounds like a "movie star"'.102

By the 1930s, valve technology had advanced sufficiently to allow for hearing aids that could be worn directly on the body (rather than necessitating batteries carried in separate bags) and this led to a rise in their usage and popularity. ${ }^{103}$ These, Kerridge conceded, gave a better quality sound and she noted that she had 'recently met two deaf physicists who have made very good sets for themselves and who are anxious to help other deaf people. ${ }^{104}$ However, the medical profession recognised growing concerns about the administration of these devices, and in 1937 The Lancet pointed out that 'the conditions under which hearing-aids are supplied to the public should include tests of the patient's response to pure tones by the audiometer, and a standardised articulation test with the instrument which it is proposed to supply for a period of trial.' ${ }^{105}$

The practices of such hearing aid manufacturers were of great concern to the NID because of their business practices, which the NID regarded as unethical. But they did not condemn the hearing aids because they did not work. Rather, firms were criticised for concerns surrounding unethical business practices not allowing free trials or refunds, and for using intrusive advertising strategies. In 1935 the NID complained about the lack of government legislation to regulate these issues, which meant that:

It is therefore open to any person, if sufficiently base, to pretend to cure deafness and to set up clinics for this purpose ... They appear in various places under different names and are sufficiently versatile in the healing art to undertake to treat other defects, such as rheumatism or asthma, when the supply of deaf persons willing to be duped in any particular locality runs short. Scarcely less despicable than the practices of quacks are the proceedings of those who take advantage of the deaf under the guise of helping them through aids to hearing. In the exaggeration of their advertising and other literature, there is little to choose between them. Hearing aids are now advertised by sandwich boards and hawked from door to door. Nothing like this is associated with any other affliction. ${ }^{106}$

Edwin Stevens of Amplivox attempted to defend his profession by forming the Hearing Aid Manufacturers' Association, which only included firms on the NID's approved list who would cooperate with the medical profession in their selling of hearing aids. ${ }^{107} \mathrm{He}$ described his decision to do this in The Lancet in 1938, when he argued that advertising was linked to fraudulent practices and 
emphasised the increasing importance of the decibel measurement as the ideal standard for the purposes of testing hearing as well as measuring noise levels.

There are, on the other hand, certain commercial firms who advertise continuously and flamboyantly in the daily press and whose sole object is to exploit the deaf public for all it is worth. Their prices are exorbitant and they charge fees for trial which are not allowed for when a purchase is made. These firms do not worry about decibels, possibly because they have not yet heard of them. ${ }^{108}$

\section{Advertising hearing aids}

For an example of one of the most sustained campaigns against hearing aid manufacturers' predatory behaviour, we return once more to the Post Office, and its use of advertising in stamp books. Stamp books were initially conceived of as a way of holding sheets of stamps together but were soon discovered to be a lucrative form of advertising. These small booklets contained stamps alongside pages of advertising features, and in the interwar period these advertisements were pervasive. In 1920, nearly 6 billion items were posted in Britain. ${ }^{109}$ These booklets were therefore highly visible publications that constituted a uniquely ubiquitous form of advertising which could target a spectrum of postal users, crossing boundaries of age, sex and class. They were utilised by various companies for advertising purposes. Indeed, certain hearing aid firms, including Ardente and Ossicaide, had long-term lucrative subscriptions to the Post Office to advertise their products within them. These were not like the advertisements discussed in the previous section, because their appearance in a Post Office publication legitimised them to the public as reputable products. Thus, these small objects had a powerful impact on driving regulation of the hearing aid industry.

Many of the people who bought the kind of cheap hearing aids advertised in the stamp books were unhappy with the devices they had purchased and complained variously to their MPs, their ministers, doctors and to the NID. Many were especially incensed because the advertisement's appearance in the Post Office stamp books had indicated to them a crucial governmental stamp of approval. For instance, one minister in Canterbury, whose wife had hearing loss, wrote to the Post Office Public Relations Department asking:

I should like to know what guarantee can be given either by the PMG or the firms advertised on enclosed extracts from books of stamps that THE DEAF WILL HEAR. These firms are well known in London to exploit the deaf and their friends for their own profit and it is degrading to a Government department 
to lend any encouragement to such people. Papers like 'The Times' will never admit advertisements of quack remedies such as appear in your stamp books. ${ }^{110}$

The Post Office's repeated inclusion of such advertisements led to a protracted campaign by the NID, the medical community, the press and several political figures, who aimed to persuade the Post Office to remove them. The NID initiated this campaign in 1936 with the emotive indictment, 'No government publication should be used to attract afflicted persons to seek relief from firms whose practices are incompatible with those usually observed in treating human suffering. ${ }^{\prime 11}$ It then went on in 1937 to request that the Post Office insert a disclaimer absolving itself from endorsement or responsibility for the devices. The Post Office refused to do so. ${ }^{12}$ In the NID's correspondence with the Post Office, it emphasised the special position that the Post Office had in terms of public influence and stressed that:

These advertisements appearing in the Stamp Books acquire an added importance in the minds of the public who seem to think that such appearance in an official publication implies a government guarantee of the articles advertised. Indeed we are often told by deafened people who have been attracted by these advertisements, 'I saw it in the Stamp Books so I thought it was all right.'113

The NID's concern about the Post Office's ability to influence the public was echoed in Parliament where the stamp book problem was brought up on numerous occasions. The first of these took place on 2 June 1933, when Sir Harold Sutcliffe, the Conservative MP and ex-serviceman, asked the Postmaster General how much revenue the Post Office derived from advertisements for hearing aids in books of stamps. ${ }^{114}$ The Postmaster General responded that 'the financial loss from the exclusion of advertisements to hearing would be upwards of $£ 3000$ a year. ${ }^{\prime 15}$ In an internal report, however, we find more specific figures: 'The revenue derived by the Post Office from advertisements in the books of stamps for the year ending 30th of September, 1936 (an average year) was $£ 16,492$ of which a very significant proportion - $£ 3073$ or $18.63 \%$ related to advertisements of appliances for the deaf." ${ }^{\prime 16}$

On 30 March 1936, Labour MP Mr William Thorne questioned the Postmaster General again about the unfair and exaggerated stamp book advertisements. ${ }^{117}$ Again the Postmaster General denied institutional responsibility, arguing that, 'Unless and until Parliament enacts further legislation making all advertisements of this kind illegal, I do not feel that there is any adequate ground on which the Post Office can refuse advertisements.' ${ }^{\text {'18 }}$ On 7 December 1936, Conservative MP Sir Robert Cary also questioned the Postmaster General on this point, making reference to the 1914 Report of the Select 
Committee on Patent Medicines and arguing that hearing aid advertisements should be prohibited under its terms. ${ }^{119}$

These objections made repeated appeal to the ruling of the Select Committee on Patent Medicines, paragraph 58(2), and the Postmaster General explained that this included fraudulent remedies such as

a large class, having an extensive sale, often at high prices, consisting of abortifacients, of alleged cures for cancer, consumption, diabetes, paralysis, locomotor ataxy, Bright's disease, lupus, fits, epilepsy, rupture (without operation or appliance), deafness, diseases of the eye, syphilis, etc. ... There should be little difficulty in identifying remedies of this class, and their treatment in the public interest need involve no doubt or hesitation. They are, and are known by their makers to be, cruel cruel frauds; and the sale and advertisement of them should be prohibited under drastic penalties. ${ }^{120}$

The Post Office's response hinged on a technicality of categorisation: that hearing aids were apparatus, not medicine. As the Postmaster General explained, 'Though deafness is mentioned, the reference is to medicines. Advertisements of medicines purporting to relieve or cure deafness are not accepted for insertion in the books of stamps; but advertisements of appliances to assist the deaf are not rejected for they do not claim to cure the disease. ${ }^{\prime 21}$ This reveals the tension over the categorisation of hearing devices as either medicines, prosthetics or technological apparatus. In this context, the label given depended very much on the agenda of the advertiser. The hybrid status of hearing aids themselves was crucial to the way they were advertised. If hearing aids were categorised as medical devices, then they would have fallen under the jurisdiction of the medical profession and the NID. By referring to them specifically as apparatus, the Post Office was able to advertise them without contradicting the Patent Medicines Act. The provision of vitamins was similarly interpretative during this period, as they were classified variously as foods or as medicines depending on fluctuating chemical categorisations. $^{122}$

False advertising of medical equipment was deliberated by Parliament in 1936 in the context of a new Medical and Surgical Appliances Bill designed to restrict the sale and advertisement of medicines and surgical appliances. This bill was designed to extend and support the findings of the select committee on patent medicines by considering medical advertising in the widest possible sense. It caused controversy, however, because it was perceived as a means of protecting and ensuring the monopoly of professional doctors over all aspects of the medical profession. This private member's bill did not get a second reading and it was suspected at the time that those opposing the bill resented the 
stronghold of the medical profession and their vested financial interests in its success. ${ }^{123}$

However, the campaign for the removal of hearing aid advertisements was supported by the British Medical Association, which made its position on the matter very clear, stating that 'the committee deplores the continued appearance in books of stamps of advertisements of hearing aids." ${ }^{24}$ This definitive statement was reported widely as part of the press campaign against the stamp book publications. The campaign was reported across a spectrum of publications and locations, receiving coverage in The Times and John Bull, as well as in the British Medical Journal, all of which condemned the hearing aid advertisements as 'misleading' and their producers as 'quacks'. Many of the articles highlighted the fact that it was especially those on lower incomes who were conned into buying useless hearing aid products. For instance, an article in John Bull explained that: 'Ex-servicemen and domestic servants are constantly induced to throw away pounds they cannot possibly afford on some of these worthless "inconspicuous aids to the deaf". ${ }^{125}$ This article was particularly detailed and condemnatory in its style, using emotive language in its depiction of the innumerable instances - pathetic in their detail and hardship - where poor people have been despoiled of their savings in a vain search among the quacks for promised relief to their deafness'. It outlined those most afflicted: 'poor people, old age pensioners, ex-servicemen and domestic servants' as well as the heroes whose 'deafness [was] brought on by war service.' ${ }^{126}$

The conservative MP Sir Francis Fremantle (1872-1943) was a crucial campaigner in these debates. He was an active figure in a variety of British medical services and an influential campaigner on issues concerning public health both within Parliament and during war service. He was a Medical Officer of Health and held presidential roles at the British Medical Association and the Incorporated Society of Medical Officers of Health, and was an active member of the NID and the Deafened Ex-Service Men's Society. ${ }^{127}$ Fremantle portrayed himself as representative of the medical profession and was prolific in writing on and campaigning for improved public health. On 24 November 1937 he wrote to ex-Postmaster General Sir Kingsley Wood to argue that:

To claim 'amazing results' from any apparatus even in the most acute cases of Middle-ear Disease and 'Stone Deafness' is a wicked lie, a danger to life and a deliberate fraud. And yet the government broadcasts this wickedness in order to obtain a few shillings more than they would from an honest advertisement. $^{128}$

The Post Office's continued refusal to remove these advertisements even in the face of this popular campaign was in part due to the flexible definition 
of hearing aids in this period. However, it was also linked to the way in which the Post Office's profits were used. In 1919 the British government had invoked a ten-year rule to reduce funding on defence, following domestic and political pressure to lower defence estimates and reduce taxation. ${ }^{129} \mathrm{By}$ 1935, however, Germany had commenced rearmament and defied the Treaty of Versailles, which prompted a rethink on the part of the British government on the subject of defence spending, with such spending duly increased throughout the 1930s. ${ }^{130}$ This, combined with the massive public debt following on from the First World War, meant that the Treasury struggled with the armed forces' demands for increased funding and the financial implications of potentially impending war. In 1938, the Post Office public relations officer, Colonel Crutchley, reflected on the fact that 'Wars are notoriously expensive and when it becomes necessary to pay for them one of the first services to be tapped for revenue is the Post Office. ${ }^{131}$ Thus, although there was pressure on the Post Office to remove these contentious advertisements, the Treasury control of the Post Office and reliance on its revenue made their removal impossible in the impoverished interwar financial context. The outbreak of war temporarily prompted the end of stamp book advertising, as civilians were encouraged by the government not to use the Post Office services during wartime. Perversely, use of the postal system increased during these years and stamp books were summarily reintroduced because of their potential for vast income generation. ${ }^{132}$

\section{Putting the user in the picture}

With the advent of the British National Health Service (NHS), the Post Office decided to modify its amplified telephones (discussed in detail in Chapter 3) so that 'deaf subscribers' could use the telephone with their new NHS hearing aids. This eventually led to the ending of the amplified telephone service and this case provides a microcosm of the issues at stake when designers produce prosthetics without consulting the users. As this chapter has argued, the increased mechanisation of hearing loss, hearing aids and hearing tests took place alongside a gradual silencing of the voices of those with hearing loss. As well as perpetuating the mechanical epistemic injustice discussed in Chapter 2, loss of user input impacted on the feasibility of the Post Office's electroacoustic services.

Plans for an NHS hearing aid were raised in 1947 after the Second World War and this device became known as the Medresco, a contraction of 'Medical Research Council. ${ }^{133}$ In 1946 the Post Office Engineering Department reported to the Telecommunications Department that the Ministry of Health 
was developing a government-sponsored hearing aid, which had not been announced to the public at that point. The quotation below outlines the Post Office's commitment to telephony for all and highlights its acknowledged expertise in hearing-assistive technologies at this period.

The present position in this respect is very different from that which existed before the war when the original enquiry was proposed, as at that time the Post Office was working practically single-handed. It now seems likely that almost all deaf people will become users of the Government sponsored hearing aid and that the best solution of the problem of affording them telephone facilities will be to design an adaptor for associating the microphone of the hearing aid acoustically with the receiver of a telephone. ${ }^{134}$

Therefore, instead of designing a new amplified telephone, the Post Office engineers decided to design an adaptor to link the new hearing aids with telephone receivers. This, they believed, would have the advantage of allowing users to link into any Post Office telephone rather than restricting their telephone usage to the home. Once the Engineering Department decided an adaptor was the most suitable solution, two means of adaption were considered: an acoustic adaptor or electrical induction. ${ }^{135}$ Electrical induction had several disadvantages and it was deemed liable to be inefficient and variable in performance as a result of electrical interference or 'howling'. Moreover, the Engineering Department was constrained because the MRC had mandated that the frequency response characteristic of the Medresco had to be maintained across all conditions of use. ${ }^{136}$ This part of the Engineering Department's report notes that this would also affect the ability to use induction 'pick up' between the Medresco and the radio. The report concluded that the hearing aid was 'primarily designed for speech. ${ }^{137}$ Building in speech as a priority over and above the need to access music or telephony was to have a long-lasting negative effect on people with hearing loss, as the aural landscape of the hearing aid users was constrained by the Medresco's focus on speech and its standardised design, which also did not allow for bone-conductive usage.

Several design constraints were imposed on the project because of the Ministry of Health's restrictions, and this was exacerbated because the Medresco was never designed to function in conjunction with the telephone; the crystal microphone precluded the use of electrical induction technology and it was impossible to make changes to the moulded case of the hearing aid to facilitate an adapter, as this would delay production, meaning they would miss the deadline for release on the NHS. ${ }^{138}$ However, the Ministry of Health emphasised that no delays or changes to the initial design of the Medresco would 
be tolerated. The crystal microphone would need to be redesigned to operate with an electrical 'pick-up' coil. This stipulation further restricted the Engineering Department's ability to experiment with electrical induction. On the other hand, the only disadvantage of the acoustic adaptor was that it would have to be physically coupled to the hearing aid and telephone every time it was used. This was therefore deemed to be the most advantageous design and so the Engineering Department began to create an acoustic coupler to link the amplified telephone with the Medresco.

Subscribers already using the amplified telephones were not consulted before the telephone was designed, because as far as likely users are concerned the subjective conditions likely to be met with will be extremely varied and cannot be satisfied equally. ${ }^{139}$ This was perhaps one of the legacies of users modifying their own telephones in the 1920s. Although there was recognition of the diverse needs of people with hearing loss, the design of the telephones was conducted entirely to the specifications of the engineers, with no input from relevant users. Although interviews had initially been considered, in 1946 the Public Relations Department declared that: 'no useful purpose would be served by undertaking interviews with deaf persons as was originally proposed. ${ }^{140}$

In addition to technical difficulties, the funding of the device was a major source of contention. There were questions from the start of this proposal over how the service would be funded and distributed. Colonel McMillan of the Research Branch in the Engineering Department raised the issue of how the telephone would be distributed in relation to the new hearing aid, asking:

Is it the intention to give a hearing aid to any person who needs it, as part of the National Health Service? It is a question whether free distribution of the adapter ought to follow as a complementary feature of the deaf aid service, and if so on what basis the distribution should be made, and by whom. As it is understood that the adapter will be capable of use with a coil office telephone as well as a subscriber's telephone, it seems clear that the distribution could not be limited to subscribers. The question of need might be determined simply by application i.e., a person having a deaf aid might be supplied with an adapter on demand. ${ }^{141}$

The Post Office obviously considered that the amplified telephone should be offered to people in receipt of a hearing aid as part of the NHS. Clearly, at this point, the Post Office conceptualised the amplified telephone as a medical device that should be free as part of a national health service. Yet still the Post Office was unwilling to cede control of the device to the Ministry of Health 


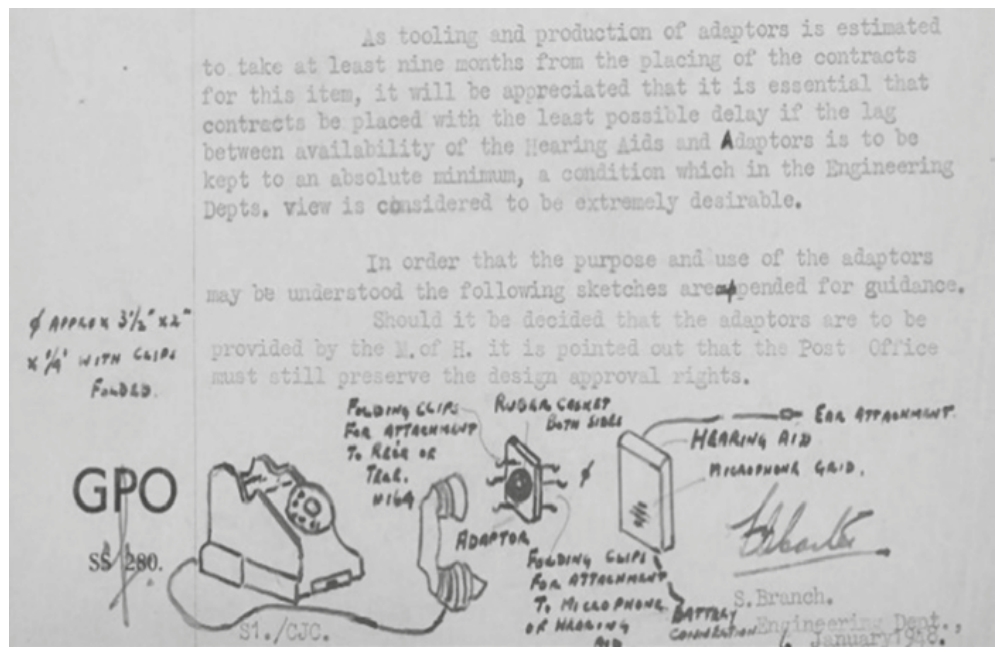

Figure 4.2 Engineer's drawing of the hearing aid adaptor, 1947

and so attempted to categorise the device as an adjunct to the telephone rather than a hearing aid, and reminded the ministry that: 'It would perhaps not be reasonable to contemplate selling the adapter when the hearing aid itself is issued free.' ${ }^{, 12}$

Once the conditions of supply of the state hearing aid had been determined the Engineering Department resumed investigations and sent the sketch shown in Figure 4.2, illustrating how the device would work for the Ministry of Health with the proviso that 'the Post Office must still preserve the design approval rights. ${ }^{143}$ While this design does illustrate clearly how the circuit would work from a detailed technical perspective, it does not actually show anyone talking on the telephone or wearing the hearing aid. The user is utterly absent. By failing to put the user in the picture, the engineers neglected to consider the social context in which the device would be used. This is in contrast to the earlier period of amplified telephone explored in Chapter 3, during which changes in design were instigated by the user and moulded to their expectations.

While the Engineering Department attempted to perfect the design, the Telecommunications Department was receiving letters from subscribers paying the excess rental for their amplified telephones declaring that they would now refuse to pay this surplus. For these 'Deaf Subscribers', the amplified telephone naturally fell under the remit of the NHS. However, the Post Office's 
request for grants for those who needed the repeaters was rejected by the Ministry of Health out of hand, as 'this is not a charge which could be accepted by this department under the National Health Service ... Their primary purpose is not medical but simply to enable a telephone conversation to be heard through a hearing aid. It would seem, therefore, that they should be sold or rented by the Post Office Telephone Service. ${ }^{144}$

Again, we see that the categorisation of the amplified telephone device was flexible, and subject to different party interests. The Ministry of Health reacted in a bemused fashion to the idea of a hearing aid for the telephone, and explained that: 'We have had difficulty in getting clear Otological [sic] advice about a telephone attachment to the Medresco Hearing Aid ... Would you be good enough, therefore to have a model sent to us, so that we can have it examined by Otologists?'145 As the body responsible for government healthcare policies, the Ministry of Health felt that the adaptor designed for hearing loss should rightly have been handled by medical experts in hearing loss. However, the amplified telephone had been designed in response to user demand, by engineers. What is abundantly clear is that users were not included in any part of this process.

It was at this point in 1949 that the Ministry of Health asserted its position regarding the need to provide telephones to the deaf. As well as deeming amplified telephony to be outside its remit, it also decreed the adaptor to be unnecessary, and one minister complained to the Post Office that: 'Under the National Health Service Act we have no power to sell "gadgets"' ${ }^{146}$ A vitriolic dispute between the two government bodies ensued. A similar struggle over prosthetic provision was ongoing at this time between the Ministry of Health and the Ministry of Pensions, as both bodies argued that wheelchairs were not part of their remit. ${ }^{147}$ The Post Office was adamant that access to telephony was an essential aspect of the health and well-being of the deaf, in accordance with its long experience in providing such apparatus. It was also quick to recognise that the issue at stake was whether the adaptor was categorised as medical or not, as this would determine which body took responsibility for enabling the deaf to access the telephone. The Post Office emphasised that it anticipated a large demand for the adaptor, and that the Ministry of Health should sponsor it:

If it decides to the contrary we could hardly sell or rent an article for attachment to an aid provided free by another Government department. If you decide that an aid to hearing ordinary conversation is medical, whilst an aid to hearing telephone conversation is not, you will have some difficulty in providing suitable answers. $^{148}$ 
The Ministry of Health disagreed and argued that access to speech was essential to health and social well-being, but access to telephony was not. Nevertheless, it recognised that this distinction was tenuous:

There is some distinction between providing a hearing aid for restoring the sense of hearing, thus enabling a person to take his part in social life - important from the health point of view - and proving apparatus to enable that person to use the telephone; we feel the latter is not for us. This distinction is one which would be difficult to make in a manner convincing to the public who would be slow to understand why we provide aids free but make a charge for the adaptor. We are hoping that we may be able to persuade you to regard this adaptor as a fitment enabling a telephone to be used with a hearing aid rather than as a fitment enabling a hearing aid to be used with the telephone. ${ }^{149}$

The Ministry of Health interpreted the 1946 National Health Act to include 'provision of surgical, medical, and other appliances. ${ }^{150}$ Despite the decree that amplified telephony did not quite fit any of these headings, the adaptors were produced. ${ }^{151}$ In fact it was a letter from the NID offering to arrange user trials of the device that rang the death knell for this project. ${ }^{152}$ When people actually used the adaptor, it became clear that the engineers had not considered the reality of hearing aid use, particularly from a feminine perspective. Most women concealed their devices under clothing. While men would easily conceal the aid in jacket or shirt pockets, women disguised the aid under skirts, making use of stockings and suspender belts to attach the aid to their body. The failure of the engineers to envision such usage meant that the clip-on attachment was very difficult for women concealing the aid to use without partially undressing to use the phone.

Reviews on performance were therefore overwhelmingly negative. Background noise was also considered to be a major problem. In terms of increased audibility, the adaptor was considered by its users to be inferior in comparison with the Repeater Telephone 17a, the standard model still available. The Post Office had capitulated to the Ministry of Health with respect to payment, and so asked testers if they would pay $4 \mathrm{~d}$ to $5 \mathrm{~d}$ for the adaptor. Most testers deemed this cost excessive. However, the most problematic issue was the fact that the adapter had to be attached to the microphone of the hearing aid, which was usually embedded within garments. The first tester to respond was a woman who explained, 'I consider the aid unsuitable for a girl who wears the aid concealed under clothing as I do. ${ }^{153}$ The second respondent also emphasised the fact that 'if, like myself, the user wears the aid concealed, it means that one has to detach the microphone case from the inside of ones [sic] apparel each time it is used.' ${ }^{154}$ Similar objections were made by all the female correspondents, 
but perhaps the most succinct expression of the problem came from the head postmaster in Malton, Yorkshire, who had been using an amplified telephone for his work at the Post Office for years. He asked if he could test out the adaptor and responded to its trial with a detailed letter. While he felt the adaptor was useful for his purposes, he candidly pointed out that:

Now, how a woman would manipulate the phone and where she would fit her aid is up to her, but she could hardly be expected to partly undress, and women are a bit keen to undisclose the aid outside, but to me - a man - I don't mind in the least as it is results I am concerned about. I must hear at all costs - regardless of sight of plastic bands etc. ${ }^{155}$

The adaptor perfectly suited the needs of its designers but not the needs of their so-called 'Deaf Subscribers'. By choosing not to consult people with hearing loss who wore hearing aids and desired to use the telephone, the Post Office had engineered a device that was completely unsuitable for the everyday lived reality of hearing loss. In fact, they had designed an aid that was inconvenient for everyone. Everyone, that is, except for a stereotypical man working in an office for the Post Office. Figure 4.3 shows such idealised use of the telephone

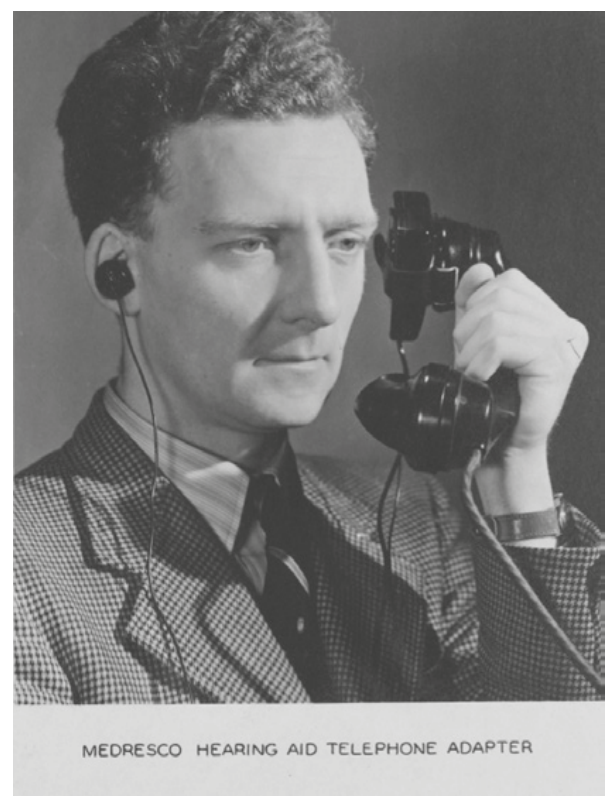

Figure 4.3 The Medresco hearing aid telephone adapter 
adaptor, with a man wearing work clothes hiding the microphone easily in his pockets.

I have previously argued, with philosopher Havi Carel, that this is a 'paradigmatic case of intersectionality, in which hearing loss and female identity intersected to produce an inability to access assistive technology which was particularly harmful to women with hearing loss. ${ }^{156}$ As demonstrated in the postmaster's quote, the extra obligation on women to hide their hearing aid amplified their difficulties in accessing amplified telephony. Women were both subjected to a more powerful social requirement to conceal hearing loss and were further impacted by the fact that the device could not be used by women wearing dresses in the way it could by men wearing suits. ${ }^{157}$

The engineers' purely technical approach did not allow for consideration of the social aspects of deafness. There was no awareness of the stigma that surrounded hearing loss or the difference that gender made to the way people wanted to use such devices. In the case of the head postmaster in Yorkshire, he had to simply hear at all costs, whereas for the female correspondents, concealment was prioritised over efficiency. Thanks to the overwhelmingly negative feedback from users, the Post Office cancelled the project. The decision not to consult end users at the start of the design process meant that the product was not acceptable to people with hearing loss who desired access to telephony.

\section{Conclusion}

I began this chapter by writing about my Mum, and my thoughts turn to her again as I conclude it. Recently she explained to me that she prefers to talk to me on the phone only while in the car - even while sitting stationary on the driveway - because by routing her mobile through the car's speaker system via Bluetooth she can ensure that she can hear me. Out of the car, she makes sure she hears the phone ringing by linking it with her smartwatch, so she can both feel and see incoming calls, alarms or texts. These are innovative individual solutions to an issue that is not widely considered to be problematic. Although there are now some mobile phones designed for the elderly which feature higher volume levels, these are notably expensive and certainly not something one could get state assistance to access. Yet during the interwar years, access to telephony for those with hearing loss was considered by the Post Office to be a crucial part of the health service. Solutions for hearing loss are now often focused on individual fixes designed to enhance access to conversation and one wonders if this would be the case if we had prioritised equitable access to a wider world of sound in the interwar period, including access to telephony, recorded music and cinema. 
In many ways, the failure to do so rested on the categorisation of speech as crucial to health, while access to sound more broadly was not so categorised. This chapter has emphasised contested categorisation issues throughout, by highlighting the different technical, medical and social influences which impacted on the categorisation of hearing aids and hearing loss during the interwar period. The drive to consider hearing as quantifiable was impacted by the need to compensate for hearing loss occasioned by warfare. Audiometry was therefore embraced as an objective test of hearing loss, which could confound malingerers and allow for quick testing of large groups of people. Furthermore, this more precise testing method expanded the numbers (particularly children) who could be categorised as deaf. This more scientific method of testing was also applied to the prescription of hearing aids, as administration was taken over by the field of medicine, despite the protestations of hearing aid manufacturers and advertisers, who emphasised the status of hearing aids as unregulated 'apparatus'. A similar interpretation of the amplified telephone as an 'adjunct' was invoked by the Ministry of Health as a way to ignore their responsibility for providing access to telephony under the NHS. While this marked the end of the Post Office's amplified telephone service, it also signalled a more technocratic approach to hearing loss, which could now be measured objectively and numerically. As the next chapter will demonstrate, strict instrumental measurement of normal sensorial functioning simultaneously defined firm thresholds of disability, which did not necessarily connect with the lives and experiences of those categorised as such.

\section{Notes}

1 Thompson, E., The Soundscape of Modernity (Cambridge, MA: MIT Press, 2002), p. 96.

2 Ibid., p. 148.

3 West, W., Room Noise and Reverberation (Post Office Green Paper No. 2) (London: His Majesty’s Stationery Office, 1934).

4 Ibid., p. 4.

5 Ibid., pp. 6-7.

6 Ibid., p. 7.

7 Thompson, The Soundscape of Modernity, p. 148.

8 West, Room Noise and Reverberation, p. 7.

9 Kerridge, P. M. T., Hearing and Speech in Deaf Children (Medical Research Council: Reports of the Hearing Committee, Special Report Series No. 221) (London: His Majesty's Stationery Office, 1937), p. 20.

10 Concert pitch was also standardised as A = 440 in the 1930s. See Gribenski, F., 'Negotiating the Pitch: For a Diplomatic History of A, at the Crossroads of Politics, 
Music, Science and Industry', in F. Ramel and C. Prévost-Thomas (eds), International Relations, Music and Diplomacy: Sounds and Voices on the International Stage (Cham: Palgrave Macmillan, 2018), pp. 173-192.

11 Thompson, The Soundscape of Modernity, p. 119.

12 West, Room Noise and Reverberation, p. 6.

13 Ibid., p. 5.

14 Virdi [Virdi-Dhesi], 'Curtis’s Cephaloscope’, p. 349.

15 Ibid. For more on the professionalisation of aurists see Virdi [Virdi-Dhesi], J., 'From the Hands of Quacks: Aural Surgery, Deafness, and the Making of a Surgical Speciality in 19th Century London' (PhD dissertation, University of Toronto, 2014).

16 What we would now determine as either sensorineural or bone conductive. Mills, 'Deafening', p. 125.

17 Sterne, The Audible Past.

18 Hughes, D. E., 'On an Induction-Currents Balance, and Experimental Researches Made Therewith', Proceedings of the Royal Society of London, 29:196-199 (1879), $56-65$, p. 58.

19 Kay, 'Inventing Telephone Usage', p. 52.

20 Hughes, 'On an Induction-Currents Balance', p. 58. Emphasis added.

21 Richardson, B. W., 'Some Researches with Professor Hughes' New Instrument for the Measurement of Hearing: The Audiometer', Proceedings of the Royal Society of London, 29:196-199 (1879), 65-66, p. 65.

22 Kay, 'Inventing Telephone Usage', p. 55.

23 Fraser-Harris, D. F., 'The Treatment of Deafness', The Lancet, 224:5792 (1934), 481-483, p. 481.

24 Report of Societies, 'Tests and Classifications of Hearing', British Medical Journal, 10:2/3540 (1928), 845-848, p. 847.

25 Bunch, C. C., 'Methods of Testing the Hearing in Infants and Young Children', Journal of Paediatrics, 5:4 (1934), 535-544, p. 537.

26 'Minutes of the Meeting of the Medical Committee of the National Institute for the Deaf, 6th of March 1931'. AOHL.

27 Fraser-Harris, 'The Treatment of Deafness', p. 482.

28 Balbi, C. M. R., 'The Audiometer and Its Application to Medical Research', The Lancet, 205:5305 (1925), 954-956, p. 954.

29 Ibid.

30 Anon., 'The Problem of the Deaf', The Lancet, 220:5703 (1932), 1347-1349, p. 1347 [summary of report by Dr A. Eichholz CBE to the Ministry of Health and the Board of Education].

31 Turner, 'Remarks on Cases'.

32 Clark, B. M. J., 'The Rejection of Psychological Approaches to Mental Disorder in Late Nineteenth-Century Psychiatry', in A. Scull (ed.), Madhouses, Mad-Doctors, and Madmen: The Social History of Psychiatry in the Victorian Era (London: Athlone, 1981), pp. 271-312.

33 Turner, 'Remarks on Cases', p. 834. 
34 Linden, S. C., and Jones, E., “Shell Shock” Revisited: An Examination of the Case Records of the National Hospital', Medical History, 58:4 (2014), 519-545, p. 531.

35 Anon., 'War Injuries and Neuroses of the Ear', The Lancet, 189:4878 (1917), 304.

36 The complex condition of shell shock has been described very well by a number of scholars so will not be repeated here. See, for example, Barham, P., Forgotten Lunatics of the Great War (New Haven, CT: Yale University Press, 2004); Reid, F., Broken Men: Shell Shock, Treatment and Recovery in Britain 1914-30 (London: Continuum, 2010); Meyer, J., 'Not Septimus Now: Wives of Disabled Veterans and Cultural Memory of the First World War in Britain', Women's History Review, 13:1 (2004), 117-138; and Scull, Hysteria.

37 Enke, 'War Noises on the Battlefield', p. 13.

38 McBride, P., and Turner, A. L., 'War Deafness, with Special Reference to the Value of Vestibular Tests', The Lancet, 192:4951 (1918), 73-74. Logan Turner's 1924 book on Diseases of the Ear, Throat and Nose is still in print today and its 11th edition is considered essential reading.

39 McBride and Turner, 'War Deafness'.

40 Arthur Hurst (1879-1944) is now best known for his MRC-sponsored filming of shell-shocked patients at Seale Hayne Hospital in Devon. See Hurst, A. F., and Peters, E. A., 'A Report on the Pathology, Diagnosis and Treatment of Absolute Hysterical Deafness in Soldiers', The Lancet, 190:4910 (1917), 517-519, p. 517.

41 'Malingering Tests' section of instruction booklet attached to audiometer, accessed at the Thackray Medical Museum, Leeds.

42 Ibid.

43 Crowden, G. P., 'Measurement of Deafness in School-Children', The Lancet, 218:5650 (1931), 1324-1325, p. 1324.

44 Anon., 'The Problem of the Deaf', p. 1347.

45 Bunch, C. C., 'Methods of Testing the Hearing in Infants and Young Children', Journal of Paediatrics, 5:4 (1934), 535-544, p. 539. For the point about precision see Anon., 'The Hearing Power of School-Children', The Lancet, 222:5754 (1933), 1328.

46 Latour and Woolgar refer to the end product as 'literary inscription' in Latour, B., and Woolgar, S., Laboratory Life (Princeton, NJ: Princeton University Press, 1979), p. 63.

47 Mills, 'Deafening', p. 129.

48 Anon., 'The Hearing Power of School-Children', p. 1328.

49 Fletcher, H., 'Physical Measurements of Audition and Their Bearing on the Theory of Hearing', Journal of the Franklin Institute, 196:3 (1923), 289-326, p. 297. This article was written while Fletcher was working at the research laboratories of AT\&T in New York.

50 Kerridge, Hearing and Speech in Deaf Children, p. 20.

51 Virdi and McGuire, 'Phyllis M. Tookey Kerridge', p. 128.

52 Anon., 'Hearing-Aids: A Report to the Medical Research Council', The Lancet, 229:5919 (1937), 340-341, p. 340. 
53 Minutes of the NID Medical Committee, 31 March 1926. AOHL.

54 Fry, D. B., and Kerridge, P. M. T., 'Tests for the Hearing of Speech by Deaf People', The Lancet, 233:6020 (1939), 106-109, p. 106.

55 Virdi and McGuire, 'Phyllis M. Tookey Kerridge', p. 130.

56 Esmail, Reading Victorian Deafness.

57 'Ears Good?', p. 370, quoted in Thompson, Soundscape of Modernity, n. 137.

58 Berger, K. W., 'Genealogy of the Words "Audiology" and "Audiologist”, Journal of the American Audiology Society, 2:2 (1976), 38-44, p. 38.

59 Ibid., p. 40.

60 Fraser-Harris, 'The Treatment of Deafness', p. 481.

61 Thompson, The Soundscape of Modernity, p. 89.

62 For a full review of Kerridge's contributions to the standardisation of audiometry see Virdi and McGuire, 'Phyllis M. Tookey Kerridge' and the forthcoming book on Kerridge by the same authors.

63 Ibid., p. 126.

64 Kerridge, Hearing and Speech in Deaf Children, p. 8.

65 Ibid., p. 29.

66 Noble, Assessment of Impaired Hearing, p. 176.

67 Kerridge, Hearing and Speech in Deaf Children, p. 24.

68 Virdi and McGuire, 'Phyllis M. Tookey Kerridge', p. 134.

69 Ibid., p. 139.

70 Berger, 'Genealogy of the Words "Audiology" and "Audiologist”', p. 40.

71 Fraser-Harris, 'The Treatment of Deafness', p. 481.

72 The first electric hearing aid was created by Miller Reese Hutchinson in 1891 through combining the telephone with the carbon transmitter. For more on the evolution of electric hearing aids see Mills, M., 'Hearing Aids and the History of Electronics Miniaturization', IEEE Annals of the History of Computing, 33:2 (2011), 24-45, p. 27.

73 The National Benevolent Society for the Deaf, Annual Reports, 1918-1952. AOHL.

74 The National Benevolent Society for the Deaf, Annual Report 1938. AOHL.

75 The National Benevolent Society for the Deaf, Annual Report 1924. AOHL.

76 Discharged Soldiers (Deafness), HC Deb 2 July 1917, vol. 95, cc. 741-742. http://hansard.millbanksystems.com/commons/1917/jul/02/dischargedsoldiers-deafness\#S5CV0095P0_19170702_HOC_98. Accessed via Hansard, March 2015.

77 Ibid.

78 'Supply of Electrophones: 1938-1939'. TNA, PIN 38/452. The Disablement Branch was a dedicated branch that had been concerned with advances in prostheses before this point and had been involved in or aware of the testing of soldiers for deaf pensions, but it was only in 1922 that it became involved with hearing aids. For example, see Inter Allied Committee for the Study of Questions Concerning the Disabled, 'Review of the Technical and Scientific Institute of Prosthesis and Surgical Apparatus', January 1922. Wellcome Library, London, MS 9200, Box 440. 
79 Letter from Director General of Medical Services to the Commissioner of Medical Services, MOP, Northern Region, 1922. TNA, PIN 38/449/9. Dundas Grant was also the Honorary Consultant Aurist to the Ministry and became a KBE in 1920 for his work in this respect. He tried to instantiate the use of the unit of 'percentage hearing' but his efforts were criticised in Kerridge, Hearing and Speech in Deaf Children, p. 27.

80 Letter from Mears Ear Phone Co., London to the MOP, 1922. TNA, PIN 38/450/23.

81 See reports: 'Aural Appliances Electrophones - supply of: 1920-1923'. TNA, PIN 38/449; 'Aural Appliances Electrophones - supply of: 1924-1926' TNA, PIN 38/ 450; 'Aural Appliances Electrophones - supply of: 1926-1929'. TNA, PIN 38/451; and 'Aural Appliances Supply of Electrophones 1938-1939'. TNA, PIN 38/452.

82 Gooday and Sayer, Managing the Experience of Hearing Loss, p. 110.

83 Ibid.

84 Ibid., p. 108.

85 Mills, 'When Mobile Communication Technologies Were New', p. 144.

86 Gooday and Sayer, Managing the Experience of Hearing Loss, p. 84.

87 Mills, 'Hearing Aids and the History of Electronics Miniaturization'. See also stamp book advertisements for hearing aids sent to the Post Office from complaining customers. British Postal Museum Archive, London (BPMA), POST 33/3481B.

88 Stols electrophone advertisement booklet sent to the MOP. 'Aural Appliances Electrophones - supply of: 1924-1926'

89 Fortiphone advertisement sent to the MOP. 'Aural Appliances Supply of Electrophones 1938-1939'.

90 Hays, 'The Social and Economic Importance of Deafness', p. 303, quoted in Virdi, J., 'Prevention and Conservation: Historicizing the Stigma of Hearing Loss, 19101940', Journal of Law, Medicine and Ethics, 45:4 (2017), 531-344, p. 535.

91 This situation could only have been deemed a success if the woman was in fact trying to deliberately waste her admirer's time and avoid having to listen to him. Mears earphones advertisement sent to the MOP. 'Aural Appliances Electrophones - supply of: 1924-1926'.

92 McGuire and Carel, 'The Visible and the Invisible'.

93 Cureton, 'Hiding a Disability and Passing as Non-Disabled'.

94 Virdi, 'Prevention and Conservation', p. 533.

95 Mills, 'Hearing Aids and the History of Electronics Miniaturization', p. 30.

96 Gooday and Sayer, Managing the Experience of Hearing Loss. I thank Karen Sayer for taking the time to explain this point to me in more detail.

97 Mills, 'Hearing Aids and the History of Electronics Miniaturization', p. 30.

98 For a fully detailed history of this phenomenon see Virdi, J., Hearing Happiness: Fakes, Frauds, and Fads in Deafness Cures (Chicago: University of Chicago Press, forthcoming).

99 Kerridge, P. M. T., 'Can Physics Help the Deaf Child?', The Lancet, 225:5811 (1935), 104-108, p. 106. 
100 Ibid., p. 107.

101 Ibid.

102 Ibid. This observation also gives an interesting insight (or inear?) into the sound quality of 1930 s cinema.

103 Mills, 'Hearing Aids and the History of Electronics Miniaturization', p. 30.

104 Kerridge, 'Can Physics Help the Deaf Child?', p. 108.

105 Anon., 'The Limitations of Hearing-Aids', The Lancet, 229:5920 (1937), 395-396, p. 395.

106 'The Eleventh Annual Meeting of the National Institute for the Deaf, July 30, 1935'. AOHL (edited for length).

107 Stevens, A. E., Letter to the Editor, 'Hearing Aids for Deafness', The Lancet, 231:5988 (1938), p. 1307.

108 Yearsley, M., Letter to the Editor, 'Hearing Aids for Deafness', The Lancet, 231:5981 (1938), p. 914.

109 In 1920, 5,716,000,000 postal packets were delivered according to F. H. Williamson, 'Post and Postal Services', BPMA, POST 72/211. 'Post Office Statistics', The Postal Museum. www.postalmuseum.org/discover/collections/statistics/. Accessed May 2019.

110 'Mr Smailes, minister of the Methodist church, at The Knoll, Elham, near Canterbury, Kent, to the Public Relation Office, May 23, 1938'. BPMA, POST 33/3481B.

111 Letter from the NID to the Postmaster General, 8 April 1936. BPMA, POST 33/ 3481B.

112 Letter from the NID to Major Tyron, Postmaster General, 16 December. BPMA, POST 33/3481B.

113 Letter from the NID to the Post Office, Major Tyron, Postmaster General, 13 May 1938. BPMA, POST 33/3481B.

114 House of Commons Sittings, 2 June 1933, vol. 278, c. 2237. http:// hansard.millbanksystems.com/commons/1933/jun/02/post-officeadvertisements\#S5CV0278P0_19330602_HOC_4. Accessed via Hansard, November 2014.

115 Response to Mr Sutcliffe, Thursday, 29 July 1937. BPMA, POST 33/3481B.

116 Internal report, Postmaster General, Slip G. Undated but judging by context 1937. BPMA, POST 33/3481B.

117 House of Commons Debate, 30 March 1936, vol.310, c. 1609.http://hansard.millbanksystems.com/commons/1936/mar/30/advertisements\#S5CV0310P0_ 19360330_HOC_68. Accessed via Hansard, November 2014.

118 Internal memorandum. BPMA, POST 33/3481B.

119 House of Commons Sitting, 7 December 1936, vol. 318, c. 1624. https:// api.parliament.uk/historic-hansard/ commons/1936/ dec/07/advertisements\#S5CV0318P0_19361207_HOC_82\%3E. Accessed via Hansard, May 2019.

120 Postmaster General Major Tyron, 6 December 1937. BPMA, POST 33/3481B.

121 Postmaster General Major Tyron, 11 December 1936. BPMA, POST 33/3481B. It should be noted that the Post Office did refuse to endorse various products and 
the list of prohibited advertisements included: alcoholic liquor, temperance (antiliquor), lotteries, imitations of Post Office marks, bookmakers, football pools, betting and gambling, birth control and rubber goods, clairvoyants, astrology and palmistry, foreign agricultural produce, offers of employment, private telephone installations, money lenders, illustrations of Royal Family, questionable or controversial books and periodicals, political advertisements, offers of employment, annuity business and patent medicines. They further restricted advertisements for building societies, anti-vivisection, electro-radiant treatment, parcel deliveries and corsets and lingerie. See 'Restriction to Post Office Advertising. BPMA, POST 33/3481B.

122 Bramwell, E., 'Rethinking Patent Medicine Culture in Britain, 1909-1949' (PhD dissertation, University of Lancaster, forthcoming).

123 'The Bill has the support of the medical profession and the pharmaceutical and advertisement trades, but opponents of the Bill seemed to suspect them of a financial interest in its success, and to resent the rigid conservatism of the medical profession'. See report 'Patent Medicines', The Spectator, 3 April 1936. www.archive. spectator.co.uk. Accessed March 2016.

124 Letter from the Council of the British Medical Association to the Postmaster General, 23 February 1938. BPMA, POST 33/3481B.

125 Sir Wyndham Childs, 'Warning to 2,000,000 Deaf', John Bull, 7 March 1936, p. 19. BPMA, POST 33/3481B.

126 Medical and Surgical Appliances (Advertisement) Bill, House of Commons Sitting Deb, 27 March 1936, vol. 310, cc. 1563-1600. http:// hansard.millbanksystems.com/commons/1936/mar/27/medicines-andsurgical-appliances\#S5CV0310P0_19360327_HOC_7. Accessed via Hansard, November 2014.

127 'Fremantle, Sir Francis Edward', in Royal College of Surgeons, Plarr's Lives of the Fellows. http://livesonline.rcseng.ac.uk/biogs/E004111b.htm. Accessed December 2014.

128 Sir Francis Fremantle to Sir Kingsley Wood (passed to Major Tyron). BPMA, POST 33/3481B.

129 Peden, G. C., British Rearmament and the Treasury: 1932-1939 (Edinburgh: Scottish Academic Press, 1979), p. 3.

130 Ibid., p. 9.

131 Crutchley, E. T., GPO (Cambridge: Cambridge University Press, 1938), p. 78.

132 'The Divergence of Postal/Telecom Profits'. BPMA, Post Office Statistics. www. postalheritage.org.uk/page/statistics. Accessed February 2020.

133 The naming of this device has led to overemphasis on the MRC's role in its creation, with attendant erasure of the work of the Post Office. Medresco was also the name used for the MRC in telegram correspondence.

134 Letter from the Engineering Department to the Telecommunications Department, 30 September 1946. BTA, TCB 2/172.

135 Memorandum, Ministry of Health Hearing Aid. 'Hearing Aid Adaptor to Permit Use of the Aid with the Telephone in Special Apparatus Fitted on Telephone Exchange Lines Rented by Deaf Subscribers. BTA, TCB 2/172. 
136 Engineering Department, Branch S Memorandum, Ministry of Health Hearing Aid. 'Hearing Aid Adaptor to Permit Use of the Aid and the Telephone.' BTA, TCB 2/172. See also MRC, Hearing Aids and Audiometers (Special Report Series No. 261) (London: His Majesty's Stationery Office, 1949).

137 Memorandum, Ministry of Health Hearing Aid. 'Hearing Aid Adaptor'.

138 Ibid.

139 Public Relations Department memorandum to Engineering Department, 27 July 1946, in 'Special Apparatus Fitted on Telephone Exchange Lines Rented by Deaf Subscribers'. Henceforth SA, BTA, TCB 2/172.

140 Ibid.

141 Memorandum, September 1947. SA, BTA, TCB 2/172.

142 Telecommunications Department to the Engineering Department, 29 July 1947. SA, BTA, TCB 2/172.

143 Letter from the S. Branch Engineering Department to the Telecommunications Department, 'Ministry of Health Hearing Aid', 27 July 1946. BTA, TCB 2/172.

144 Ministry of Health to the Post Office 30 April 1949. SA, BTA, TCB 2/172.

145 Ministry of Health to G. P. Wooley, Telecommunications Department, 26 May 1948. SA, BTA, TCB 2/172.

146 Letter from Ministry of Health to Post Office, June 1949. SA, BTA, TCB 2/172.

147 Woods, B., and Watson, N., 'In Pursuit of Standardization: The British Ministry of Health's Model 8F Wheelchair, 1948-1962', Technology and Culture, 45:3 (2003), 540-568, p. 554.

148 Post Office to the Ministry of Health, 14 May 1949 (emphasis added). SA, BTA, TCB 2/172.

149 Ministry of Health reply to the Post Office, June 1949 (emphasis added). SA, BTA, TCB 2/172.

150 Woods and Watson, 'In Pursuit of Standardization', p. 555.

151 Although they were designed by the Post Office research and engineering departments, the Plessey Company provided the equipment to make the prototypes.

152 This trial was with members of the London League for the Hard of Hearing (which was also testing out the Medresco).

153 Letter from NID to Post Office Headquarters, St Martin's Le Grand, London, 16 October 1950. SA, BTA, TCB 2/172.

154 Letter from NID to Post Office Headquarters, St Martin's Le Grand, London, 13 December 1950. SA, BTA, TCB 2/172.

155 Letter from Head Post Office, Malton to R. W. Clarke (Sales Division), 26 April 1951. SA, BTA, TCB 2/172.

$156 \mathrm{McGuire}$ and Carel, 'The Visible and the Invisible'.

157 Ibid. 